\title{
INFLUENCIA DE DOUTORA WANDA DE AGUIAR HORTA NA EEUSP
}

Nara Sena de Paula

l'AUla, N.S. de. Influéncia de Drą Wanda de Aguiar Horta na EeUSP. Rcv. Esc. Enf. USF, São Paulo, 21(n\%/especial) :3-9, 1987.

Vinte anos de convivência profissional com Dra Wanda de Aguiar Horta, tornaram-nos responsáveis por apresentar, nesta ocasião, o reflexo de sua influência na EEUSP.

Cinco anos já se passaram desde seu falecimento, porém sua presença se faz sentir ainda com um forte impacto emocional e, creio, com melhor perspectiva, já que hoje, a visão histórica de seu evoluir, em vinte e dois anos de trabalho nesta Escola, torna possivel, uma focalização mais real e menos pertubadora de suas crenças.

Por que crença? Por ser uma idealista, pioneira e cientista, Dra Wanda precisava crer nas suas propostas; porque seu saber teórico, muitas vezes aplicado na prática e no ensino, precisava de tempo para ser testado, digerido e experimentado pela comunidade de enfermagem.

Mas sua crença tornara possivel um acreditar latente em todos os que a ouviam, liam seus trabalhos ou tinham a oportunidade de partilhar com ela de suas idéias e sua teoria.

Não é fácil se fazer reconhecido em sua própria casa. E não foi para Dr: Wanda. Inúmeras barreiras tiveram que ser enfrentadas; algumas foram demolidas, outras apenas arranhadas, outras ainda persistem.

Mas a semente do seu saber foi lançada e, independente de qualquer expectativa, hoje flui como a serenidade de um rio que corre, na certeza de que segue a direção de sua foz. Tão forte foi a semente, tão presentes seus frutos, que nos contatos que temos tido com os diversos setores desta Escola para sentir sua influência, tornou-se comum ouvir: "Não se pode medir, por imensurável, a contribuição que Dra Wanda nos deu".

Mestra por qualidade inata e diuturnamente aperfeiçoada quer nos estudos auto didatas ou não, em leituras especificas ou cultura geral, aulas ou cursos, por contato com alunos de todos os niveis, desde os leigos, ou os de treinamento em serviço, até os de Pós-Graduação, em salas de aulas, grupos de discussão ou campos de estágio, esteve sempre presente sua ação de didata emérita. Por tais razões, outras não houvessem, sentimos não tenham hoje, nossos alunos de graduação, o privilégio que tivemos de tê-la como professora. 
Era a professora que recebia os calouros e se tornava responsável por eles durante todo um ano. Não o fazia só por dever de oficio, mas com a vocação que a tornava nosso modelo. Era a enfermeira que queríamos ser; era a professora com quem tínhamos o que aprender; era a mulher que se tornava nossa amiga.

Pensando em sua ação nesta Escola, temos que lembrar de sua influência sobre os alunos, pois $\mathrm{Dr}^{\text {a }}$ Wanda não tinha preconceitos no que ensinar e, assim, sua atividade começava no aspecto de cada aluno, quer uniformizado ou não, pois ensinava desde os mais simples cuidados de higiene pessoal e profissional até o comportamento em refeitório e banheiros. Não íamos com uniformes do hospital para o almoço, assim como não se via um pedaço de papel no chão dos banheiros, porque desde Introdução à Enfermagem, aprendiamos os princípios que norteavam estas pequenas ações cotidianas.

Cada aluno se sentia uma pessoa importante, porque era tratado por Dra Wanda como tal. Sempre tinha tempo para ouvi-lo; não esquecia seu aniversário, seus problemas e suas aptidões.

Talvez por isso, tenha sido várias vezes paraninfa de turma.

Foi uma das primeiras professoras a utilizar os conhecimentos dos alunos naquilo que hoje chamamos de monitoria, começando a oferecer serviços aos alunos, com bolsas de estudos tiradas de seus próprios recursos financeiros, para datilografia, arquivos, levantamento de dados bibliográficos ou para pesquisa, no laboratório de enfermagem, etc. Os alunos de fora da cidade, ou fora do País, eram seu "xodó", recebendo-os com freqüência em sua casa para torná-los menos isolados e mais protegidos.

Adorava dar aulas que eram sempre enriquecidas por sua cultura geral e científica e seu maior prazer era acompanhar os estágios dos alunos.

Não encontraria um exemplo melhor de sua dedicação aos alunos como pessoas inteiras, pelos quais se sentia responsável, do que o fato de, nos anos obscuros das ditaduras, em que a perseguição ideológica às universidades era uma situação extremamente difícil quando poucos se dispunham a demonstrar simpatia por qualquer pessoa que viesse, mesmo de longe, a ser identificada como tendo idéias "esquerdistas", $\mathrm{Dr}^{\mathrm{n}}$ Wanda chegou a ir às prisōes para, com risco de sua própria vida ou de sua familia, prestar o apoio pessoal a alunos desta Escola que foram detidos.

Sua formação eclética, incluindo licenciatura em História Natural, tornou possível sua influência na organização da EEUSP quando deixou de ser anexa à Faculdade de Medicina (1962) para ser Unidade independente da USP.

Nessa época, se tornou impossivel a utilização dos laboratórios da Faculdade de Medicina e a EE teve que montar seus próprios. Além de assumir a coordenação das disciplinas básicas, de ministrar a maioria delas, como Anatomia, Fisiologia, Microbiologia, Parasitologia, Embrio- 
logia, Histologia, Biologia, Farmacologia, além das específicas de enfermagem: Introdução à Enfermagem e Fundamentos de Enfermagem, precisou criar os laboratórios de Anatomia, Histologia, e o de Microbiologia. Para isto, foi necessário procurar apoio fora da USP, o que foi conseguido com os professores da Faculdade de Medicina da Santa Casa de Misericórdia de São Paulo que deram as aulas de Fisiologia e que forneceram até peças de cadáveres que foram acondicionados em caixas d'água de amianto, testadas no IPT para verificação de sua resistência ao formol.

Seu gosto pelo ensino era irradiado para nós, suas assistentes, nessa época, e dela lembramo-nos como uma das fases mais produtivas de nossa vida acadêmica, principalmente pela riqueza de interesses que partilhávamos.

Mais tarde com a reforma universitária, em 1970, tendo as disciplinas básicas sido distribuidas pelos diversos institutos, estes laboratórios foram desativados. Foi uma perda, para a $\mathrm{EE}$, para os alunos, para a Enfermagem. Porque o ensino não pode mais ser articulado como fazíamos neste período anterior, quando as aulas de Anatomia, de Histologia, Embriologia, Fisiologia, Microbiologia, Patologia, Parasitologia, Psicologia, Saneamento, Estatística, Nutrição e outra, eram dadas de forma sincronizada com Introdução ou Fundamentos de Enfermagem. Jamais, depois desta época, foi possivel organizar uma estrutura curricular assim articulada.

A influência de Dra Wanda, porém, neste setor, ainda se faz sentir, pois foi o elemento indicado pela EEUSP para compor a Comissão Especial de Estudos para Instalação dos Cursos Básicos na Universidade de São Paulo, em 1965. Muitos dos programas das ciências básicas para a enfermagem, tiveram a sua orientação inicial.

No entanto, um laboratório ainda existe nesta Escola e agora se ampliando, que foi criado também pelo apoio, incentivo e colaboração de $D^{a}$ Wanda que é o Laboratório de Nutrição. Sua idéia inicial, era manter o laboratório de Microbiologia funcionando, porém, com a reforma universitária, não foi possível mantê-lo e, até agora, não foi possivel reconstruí-lo. Mas o Laboratório de Nutrição é hoje usado por diversas disciplinas, diversas Unidades da USP e mesmo por várias Universidades, inclusive por bolsista da FAPESP.

Foi uma das primeiras docentes da EE a usar o computador em suas pesquisas e, temos certeza, estaria contente se pudesse saber que hoje, temos um Centro de Informática nesta Escola. Da mesma forma, o Centro Assistencial de Enfermagem, criado e mantido pelas docentes da disciplina de Enfermagem Médico-Cirúrgica, que utilizam em sua sistemática de ação a Consulta de Enfermagem, é um reflexo de sua atuação e influência de seus ensinamentos.

Poucos são, atualmente, os docentes desta Escola que não sofreram sua influência. Muitos de nós fomos suas alunas de Graduação, de Pós- 
Graduação, recebemos orientação de teses e de pesquisas. Quantas de nossas fichas de aulas têm sua letra corrigindo ou acrescentado alguma coisa!.. . Mas principalmente, dela, nos ficou o fundamental, isto é, a necessidade de construirmos um saber de enfermagem que se baseie em sólidos princípios científicos. Nos legou uma Teoria de Enfermagem para podermos expandir nossos conhecimentos a partir de propostas que nos levem a uma ciência da enfermagem. Nos deixou pressupostos filosóficos que embasam os conhecimentos científicos. Hoje, temos toda a EEUSP empenhada em reformular seu Currículo. Os estudos tiveram início com as primeiras propostas de $\mathrm{Dr}^{n}$ Wanda, em plenárias do Departamento ENC, onde procurava alcançar, em conjunto, os conceitos básicos de enfermagem. Mais tarde foram organizados Simpósios sobre filosofia e marco conceitual da EEUSP. O primeiro Grupo de Trabalho sobre currículo fundamentou suas propostas de mudança nos materiais, fontes de referências e bibliografia organizados sob a orientação inicial de $\mathrm{Dr}^{\text {s }}$ Wanda, naturalmente ampliados com novas fontes de informação e novas perspectivas.

Hoje, continuamos a propor mudanças, porém o fundamental está lá: basear o ensino em uma filosofia, propor um marco teórico, estabelecer uma linha de ação única, seguir uma metodologia de assistência de enfermagem e procurar atingir um objetivo comum.

O espirito democrático, auto-suficiente e aberto a todas as mudanças, apresentado por $\mathrm{Dr}^{\text {a }}$ Wanda, tornou possivel a experimentação de novos rumos entre os docentes da EE e, em especial, os de seu departamento. Ela acreditava que cada docente era responsável por suas atribuições e as desenvolveria a contento; tanto, que foi a responsável por não termos hoje, nós docentes, que assinar ponto de entrada e saída na EE; mas, ao mesmo tempo, não abria mão de sua coordenação didática, promovendo reuniōes e cursos, orientando, ensinando, corrigindo, escrevendo trabalhos em colaboração com outros docentes, propondo mudanças, utilizando novas técnicas de ensino, trazendo aos docentes toda a informação nova a que tinha alcance. Prova disso é o acervo de nossa biblioteca,altamente enriquecido por seus pedidos de aquisição, quer de livros nacionais quer de estrangeiros, bem como de periódicos e publicações avulsas; não só solicitava aquisição pela biblioteca, como formava a sua própria, que estava sempre a disposição de todos. Estimulava a circulação de revistas e livros.

Assim também, o acervo material audio-visual e do Laboratório de Enfermagem foi grandemente aumentado por suas solicitações, não o sendo mais, apenas, pela freqüente justificativa de falta de verba.

Interessante notar que quando perguntamos à Secretaria do Departamento ENC o que achava que ainda perdurava no Departamento como influência sua, pensando receber alguma resposta de ordem administrativa, ouvimos o seguinte: "O espírito científico; este é fruto de seu empenho; foi ela que começou com trabalhos de pesquisa e levou todos a desenvolver o espírito científico". 
Esperamos que seu espirito pacifista, ao mesmo tempo de luta para vencer barreiras, também tenha permanecido.

Dissemos, inicialmente, que não foi fácil o começo. Tanto não foi, que até dificuldades para publicar suas idéias Drit Wanda enfrentou. Mas isto não foi intransponivel para ela. Criar sua revista era difícil, mas não impossível! E sua Revista Enfermagem Novas Dimensões foi criada e se tornou um dos melhores veículos de divulgação das publicações docentes, que eram estimulados a publicar em todos os periódicos disponiveis e apresentar seus trabalhos em Congressos, Simpósios ou outros eventos, inclusive nas Reuniōes Anuais da SBPC.

Chefe democrática, sobretudo humana, procurou no Departamento, suavisar relações, com atitudes muito pessoais de lembrar os aniversários, de trazer uma recordação para cada um no final de suas viajens, de cumprimentar a todos com um cartão especial, em particular na Páscoa e no Natal; de promover festas de congraçamento social; sobretudo, estimulava e prestigiava cada um. Atendia a todos, sem exceção, mesmo aqueles que, por suas características de personalidade, ninguém queria atender.

Sofreu na pele, a ação de pressões que uma liderança democrática faz surgir, mas não abjurou de seus princípios sociais, apesar de algumas vezes ter sido obrigada a fazer cumprir decisões de Colegiados às quais deplorava profundamente.

A Estrutura Curricular da EE para o curso de Graduação conta, nos programas de sua disciplinas, com a marca indelével de sua permanência entre nós, pois, com exceção de uma disciplina que informou rão utilizar em seu programa a teoria ou a sistemática proposta por $\mathrm{Dr}^{\text {: }}$ Wanda, as demais disseram conter em sua programação ensino específico das Necessidades Humanas Básicas, do Processo de Enfermagem, da Sistemática de Assistência de Enfermagem ou do Planejamento de Assistência e uma delas informou que suas idéias são fontes geradoras de reflexões acerca do fazer da enfermagem e estímulo para desenvolvimento de estudos sobre metodologia de assistência específica. A maioria relatou aplicar o processo adaptado; apenas uma se referiu a ministrar a metodologia de sua teoria, e não apenas o Processo isolado, e esta mesma foi a única a fazer referência a dar continuidade ao ensino das disciplinas anteriores da grade curricular.

Mas isto tudo é só um começo; um lento caminhar para a foz do rio, quando seremos capazes de lidar com Teorias e seguir o leito preparado para o correr tranqüilo das águas do saber.

Quanto aos cursos de Pós-Graduação, a presidente do CPG assim se manifestou: "A Pós-Graduação existe porque existiu Dr: Wanda".

E a professora Evalda Cançado Arantes, desde o início envolvida também com a Pós-Graduação, perguntou: - "O que não é influência 
dela na Pós-Graduação?" e respondeu logo a seguir a uma breve reflexão: "Acho que só os erros".

O início começou com sua orientação a nós, Pós-Graduadas pelo curso anteriormente existente na EE que dava o direito, até 1972 de se prestar concurso de Doutoramento pela defesa de uma tese.

Realmente, a idéia de abrir o curso de Pós-Graduação na EE nos novos moldes, inicialmente com o Mestrado e tão logo esta fosse aprovado, propor o Doutorado, foi de Dr. Wanda. Tendo sido ajudada na organização da estrutura do curso por Dr: Maria Rosa Sousa Pinheiro e Dr: Anayde Corrêa de Carvalho foi, entretanto, todo o seu empenho, a organização curricular, o convite aos professores e sobretudo a sua fé de que o curso seria criado, independente de todas as forças contrária existentes na Câmara de Pôs-Graduação da USP, inicialmente, para a criação do Doutorado, que tornou realidade o nosso curso. Era quem acreditava que as barreiras seriam vencidas, mesmo quando eram colocados obstáculos para não serem transpostos, como o caso da exigência de um curso único ministrado por duas Unidades independente de dois campus distantes, e seu estímulo às comissões envolvidas mantinha o ânimo elevado e as esperanças acesas. A Pós-Graduação se tornou parte integrante de seu ser, pois só assim se compreende sua inestingüivel capacidade de trabalho assumindo várias disciplinas, onde coordenava, dava aulas, acompanhava estágios e seminários, participava de inúmeras bancas examinadoras, orientava trabalhos, em especial os de pesquisa, avaliava a produção científica e estimulava a publicação.

Todos os programas das disciplinas aprovadas para a grade curricular da Pós-Graduação passaram por sua análise e orientação. Acumulava com isto todas as atividades administrativas que exigiam suas funçōes de presidente, Vice-Presidente ou membro da CPG. Ainda devemos a ela a abertura do mestrado pois, quando este foi autorizado, só o foi para Fundamentos de Enfermagem e Drit Wanda recebeu todas as primeiras 57 alunas em 1973, enquanto se aguardava que as demais áreas fossem liberadas, o que ocorreu em 1975. Muitos dos programas aprovados por ela continuam em vigor, uma vez que sua proposta foi a de que os programas tivessem uma abrangência tal que poderiam se manter constantes enquanto a programação anual, baseada neles, poderia ser evolutiva.

Era um exemplo para as alunas do Pós-Graduado em relação à carreira universitária e a trabalhos de pesquisas e publicações.

Organizou o Departamento de Enfermagem Médico-Cirúrgica em 1970 que até hoje mantém muitas das linhas de ação propostas por Dr* Wanda.

Participou como membro ou como presidente de inúmeras comissões da EE, principalmente as relacionadas ao ensino, tendo sido até mesmo 
Presidente da Comissão que estudou a reestruturação do quadro docente.

Em fevereiro de 1981, quando se aposentou, o Prof. Dr. Carlos da Silva Lacaz externou os sentimentos de todos os funcionários, professores e alunos da EE dizendo do apreço que lhe era atribuido por dignificar a classe a que servia e, pela contribuição que havia dado ao desenvolvimento da enfermagem em nosso país, lhe outorgava o título de professor Emérito, a ser entregue posteriormente.

E o magnifico Reitor da USP, nessa ocasião, Prof. Dr. Waldir Muniz Oliva lhe assegurou oficialmente que seus ex-alunos e colegas da EE honrariam as liçōes aprendidas e dariam continuidade ao ensino de tudo aquilo que havia logrado difundir em benefício da ciência e da cultura de nosso país.

E o que estamos tentando cumprir! 